\title{
Developmental Research of Harmonious Education Thought in a Sociological View
}

\author{
Liu Shuang \\ Information College. \\ Zhongkai University of Agriculture and Technology \\ Guangzhou, China \\ e-mail : liu_chuanju@126.com
}

\author{
Liu Chuanju \\ Information College \\ Zhongkai University of Agriculture and Technology \\ Guangzhou, China \\ e-mail : liuchuanju@zhku.edu.cn
}

\begin{abstract}
-harmonious education reflects that the fusion of eastern and western education concept, which is a necessity for high education social attributes and natural quality to couple. Chinese and foreign history of Education all along penetrates " whole person education thought, With China's implementation of the microscopic level of the Harmonious Education -- Quality Education, though they have a lot in common, there are still significant differences in The emphasis on individual development and social development dialectical relation and human personality and the sense of social responsibility. Harmonious society calls of harmonious education, only by way of higher education itself and social adjustment and beyond, in order to promote the harmonious development of higher education system..
\end{abstract}

Keywords- sociology; harmonious education; holistic Education

\section{INTRODUCTION}

2012Global innovation index(4144.832,-27.67,-0.66\%) reported ,China is in the position of 34 . On July 6th, the national science and technology innovation conference was held in Beijing. Nine of the central committees attended the meeting and put forward clearly, China will become a innovative country in 2020 . The meeting reveal that the future of China has an important policy is that we should strength the position of business technology innovation.

Global economic renew is very hard now. In the background of economic downing pressure, Innovation meeting show that the top of national policy makers is visionary. We should try our best to handle the history opportunity' $s$ important decision of the new round of science and technology.

Nowadays, human get access to a knowledge economic times that the knowledge is height intensive and the science and technology is height intensive. The essence of knowledge technology is innovate. The future society of the comprehensive national strength's competition, in the final analysis is the competition of knowledge innovation. The importance of the creatively wisdom of human's talent development never like today that the reality is so incisively and vividly. To speed up the innovation talent training is an important strategic choice in the fierce international competition to win the initiative. National medium and longterm education reform and development plan outline (2010-

2020) are put forward that adhering to the people-oriented, quality-oriented education is the education reform and development of strategic themes. The most importance of the themes is gearing to the needs of all students, promoting allround development of students, enhancing student services national and people's sense of social responsibility, the enterprising innovation spirit and practice ability of problemsolving[1].

Quality education in our country as the reform of the 21 st century, the most fundamental and concentrated expression in the practice topic is cultivating and pursuiting the perfect of personality. It emphasizes the moral, intellectual, physical and so on specific implementation in each student. Paying attention to the comprehensive harmony's development of intelligence factors and non-intelligence factors .It also is the ultimate goal of the harmonious education. This article study the harmonious education thought's development history, represent the east and west culture collision and blending on the concept of harmonious education from the perspective of sociology.

\section{THE HARMONIOUS EDUCATION THOUGHT IS A SOCIAL ATTRIBUTE OF HIGHER EDUCATION}

Higher education takes what kind of functions of talent training and cultural mission, is restricted by the external social factors. It has corresponds with the economy and the characteristics of culture, which for three socials ( that is, agricultural society, industrial society, industrial society and knowledge economy society) in the history of mankind, higher education' bounden duty also experiences three different stages of development[2].

Characteristics of industrial society is the professional production technology, automation, standardization, mass production technology, etc. The characteristics of products are standardization, seriation, popularization, mass, etc. The industrialized society stylized, homogenization, the tool rationality, the higher education personnel training mode is characterized by " focus on professional education mode of cultural imitation. " The goal of talent training is the counterpart, at the way of talents and experts on hand, from the training process, is a narrow professional education mode, or instrumental rationalism education model. The basic characteristic of knowledge economy era is a combination of

knowledge and economy, innovation is the essence of knowledge economy.

In the motive force of the development of knowledge economy, the essential attribute of knowledge economy is coming from the production of knowledge. Therefore the higher education would have no choice but to adhere to the value orientation in the future, pay attention to the training of innovative talents of high quality.

Basic properties of knowledge economy is that the driving force of knowledge economy comes from the production of knowledge. Under the restriction of the economic society, higher education will no choice but to insist on the value orientation of the future. Famous American futurist Toffer. A in 1970 proposed that education system in the era of

Identify applicable sponsor/s here. (sponsors) 
knowledge economy should care now turn to care future. UNESCO in 1972 in the book Learning to Be pointed out : “ those who devoted in developing education programs need to have a broader insight for the future, should take this view as a definite objective rather than a vague, rely on the fate of the future"[3]. The success of education and is the standard that educatee not educated to bid farewell to the past, and a new future for courage and ability[4].

The knowledge economy era of social harmony need highquality personnel training under the concept of harmonious education support. And high quality training in the knowledge economy era is the bounden duty of a high school. Want to responsibility for the bounden duty, we will be adhering to the concept of harmonious education, deepen the high school talents' training model reformation. Actualize quality education, focus on cultivationn of students' sense of social responsibility, creativity, practical ability, pay more attention to education of scientific spirit, humanist quality education and life-long learning ability. In training style, should pay attention to the combination of learning and thinking, the unity of knowledge and practice, teach students in accordance with their aptitude, advocate and actively promote the elicitation, discussion teaching, inspire independent thinking and innovation consciousness, pay attention to learner's collecting and processing information acquiring new knowledge, ability, ability to analyze and solve the problems and the solidarity and social communication ability.

Based on analysis of the sociological perspective, the aim of higher education centre on a certain degree of nature and function of social education, reflect the social and times to cultivate people's certain requirements. restricted by the society and the times. At the meantime it show clearly direction for educator and educatee. In the long process of education practice, people start from their own dream to give the education to cultivate in the different connotation.

\section{THE THOUGHT OF HARMONIOUS EDUCATION IS THE COLLISION AND BLENDING OF EASTERN AND WESTERN CULTURE}

In the western history of education, the development of harmonious education thought has mainly experienced three stages : that is ancient Greek times, Renaissance and industrial revolution. The first who put forward the concept of Harmonious Education in the period of ancient Greece is Aristotle ,Socrates, Plato. According to the slavery society needs in politics and economy, discusses the implementation of dealing with children, morality, wisdom, beauty and all-round and harmonious development view of education.

From 17th to the 18th Century after the Renaissance, its representative including Comenius to Rousseau in the eighteenth Century, Didero, lmmanuel Kant and others. After British and French bourgeois revolution in Europe, entered later-day society. In order to adapt to the needs of the capitalist society, some educators proposed "gentlemen education". Such as Britain' Locke in his famous book "Thoughts Concerning Education" thinks: "A deal with their own things, have the sense of virtue and capable person, much more than the one without the quality of great scholars."In eighteenth Century the French enlightenment scholars, educator Rousseau start from out of the bondage of feadal old education to children's physical and mental development, requires that education should fit to nature, develop child's various potential[6] .

Holistic Educationist is also said perfect education, it grow up in Europe in the seventy of the 20th century. Formed a world of whole person education reform movement .

In 19th century the European famous education theorists and practitioners Johann Helnrich Pestalozzi aimed at the drawbacks of the education at the time, and the need of industrial society, gives harmonious theory with extremely rich and profound content. PeiShi believed that nature is threefold: (1) the nature of animals - its natural products; (2) social nature - it is the product of the social order; (3) - it is the product of creativity in the moral nature. So there will be a natural person, social and moral people. Natural person - that is, purely for self is born; Social person - that is, by common agreement together with compatriots; Moral people - that is, regardless of its original need and social obligations, people look at things from their own inner values.

Based on the research of the triple nature, PeiShi believes that people's development is not only natural, but also has social purpose, therefore, education measures is to be suitable for human nature, and in accordance with their social conditions. Is "is alive and precious is the development, development of personal talent inner strength, make its after exercise, make the person can do it, only can reach his rightful place in society. This is the ultimate goal of education" all landowners[7].

In June 1990, the 80 in the world in support of the whole person education scholars in Chicago signed in Chicago "education 2000: holistic education" (i.e., the declaration of Chicago), the system elaborated the whole-person education concept. On the current education system and human society in the United States are worried about the cultural, social, ecological crisis happened, the ten principles of education reform is put forward.

The declaration of Chicago's core idea is that education goals. Complete education should train people, make the person is in body, knowledge, skills, and the development in such aspects as morality, intelligence, creativity, and become a real person, a person as a person, not just an employee, the human resources of a country, a political or economic tools today.

Ideas of harmonious education in China can be traced back to 2500 years ago Confucius. He pursues the education goal is to develop a saint, a gentleman or adult. And such people should get more harmonious development. Such as the lower level is the developing request of the "adult". What is the "adult"? According to zhu xi on the four books, the analects of Confucius variorum "cloud:" adult, Jude said." In Confucius' opinion, in the know, love, brave, and so on various aspects have been the development of the arts, can be referred to as the "adult". It is from this idea, Confucius stressed the united wisdom, benevolence and courage, to cultivate learners called "adult", "the gentleman" or "saint". And intelligence and the unity of the kernel, brave "three moralities", tell from the pedagogy, essentially intellectual education ("know "), education (" benevolence "), the unity of the sports (" brave "); From a psychological point of view, is the knowledge ("know "), emotional (" benevolence "), will ("brave "). This two kinds 
of unity, human all-round development laid the necessary foundation.

During the warring states period xunzi also puts forward the culture of "adult" education purpose. And claims by all (people development comprehensive knowledge, talent, quality, etc), do (development thoroughly, extreme), raw (the study of essence of the development and perfect) to be implemented pet-name ruby[8].

The western han dynasty dong inherited Kong Ziren of unified thought, made clear on the issue of coordinated development since in this paper. A person, he thought, no, only, just like "fuck the soldier weapons (good)," making bad business. Also, wisdom, not only, also can such as "fan and take a good horse", reach the purpose.

1906, the famous thinker and educationist wang guowei about rich and typical significance, he wrote in the article "on the purpose of education" : "what is the purpose of education: to make people full of character. What is the character of the completely? Refers to person of ability is developed and the harmonic is also." And pointed out that "completely SanDe of characters is not true. To achieve this ideal,

And since the matter of education, from the education is divided into three parts: intellectual education, moral education (will), aesthetics (lust) is also. "Of wang guowei's thought of harmonious education, based on Confucius institute think tank, kernel, brave, harmonization and unification of the four traditional education thought as the foundation, and absorb the modern psychology knowledge. In addition, CAI yuanpei's education (army national education, materialism education, moral education, world outlook education and aesthetic education, tao xingzhi's hands and brain connections that combine with the harmonious development of education thought[9].

\section{BEYOND THE OF HARMONIOUS EDUCATION THOUGHT IN THE ERA OF KNOWLEDGE ECONOMY}

Harmonious education thought in the western originated in ancient Greek culture, forming the Renaissance, developed in the enlightenment, in the modern society is increasingly perfect.

In China, from 2500 years ago, Confucius said, "adult", to the warring states period ", to the best of all, the essence "of xun zi, LiuShao dong of western han dynasty, three kingdoms period, until the Ming dynasty Wang Shouren quite explicitly put forward whole person education concept" open its perception ", "regulate its temperament", "his ambition means" or "anti-popular character its ambition means", "guide" with courtesy, "turmoil" of its blood, "solid beam of the steel skeleton," eventually "in neutral and the reason". These give people the proposition of harmonious development is the fundamental aim of xingjiao education since the ancient times in China.

Harmonious education is education ideal and education can bring humanity's greatest reward. The purpose of education is not just .High knowledge level of educators; Also not only is the ability to strive for ascending humans and nature; Education is more important purpose is to let suffer pedagogue to have harmonious psychosomatic, feelings of harmony of the world, the construction and living in a harmonious environment.
Harmony is first man of physical and mental harmony. Mental and physical harmony, is the unity of the personality and harmony. Personality harmonious is that people are so reason to exist, is the driving force for the development of the people so, is people's pursuit of the ultimate goal. Desires to reach a harmonious state, first of all should be all-round development of body and mind of their own. These two aspects are equally important and interdependent.

History of Chinese and foreign education throughout the whole person education thought, and China's current implementation of the micro level of harmonious education, quality-oriented education, from the training objectives to teaching methods emphasize all-round development, attaches great importance to the students' cognition, emotion, interest and potential of the play, and attaches great importance to the meaning of learning. These are reflected in the quality education. Though they have many in common, but there is still a significant difference between the dialectic relationship, personal development and social development and people's perfect personality and the social sense of responsibility.

\section{A. Emphasize the Personal Development and Social Development of the Dialectical Relationship}

"Cultivate all-round harmonious development of the social development need" this goal is classic marxism about person's full scale development theory of reality. Marx and Engels on the basis of extensive investigation, from the "people's allround development" is the inevitable developing law of industrial production history. Engels in the communist principle, points out that the comprehensive development of man is a "new man", under the condition of large industrial production is physical strength, intelligence get all-round development of people, also is a harmony of body and mind, rather than unilateral deformity. Marx, Engels and the all-round development of all the members as a condition of individual comprehensive and free development, they say: "only in the collective, individual can get all-round development of the means of", that is to say, only in a harmonious environment, talents can develop harmoniously, and this requires education can "environment education, the overall optimization", in the harmonious education to cultivate the harmonious development of man.

About man's all-round development. Marxism from the people is "the sum total of social relations", for the social reality at that time people's one-sided development of capitalism, and combining with the development of future communist people's social thought, and put forward the thought of man's all-round development. The so-called man's all-round development, to include three aspects: the meaning of is the harmonious development of physical and mental; People's ability and quality of the various development; The unity of personal development and social development[10].

Marxism believes that human development must be coordinated with the development of society, individuals are likely to get the real all-round development. Every man is always in a certain historical conditions and social relationships in social activities of social reality, he can't be separated from social life and people. 


\section{B. Emphasize the Person's Perfect Personality and Social Responsibility}

Founding leader MAO zedong in February 1957, the education experience, summed up China's new-democratic period in "on the correct handling of contradictions among the people" in the said: "our education policy, should be educated in the moral education, intellectual education, sports development, several aspects have been become a worker with socialist consciousness of culture." This is the first time since the founding of the formal adoption of the socialist education policy. In the presentation of this approach, first proposed the concept of quality education.

Comrade zhou enlai pointed out: "the moral education, intellectual education, physical education is mutual connection, mutual combination of the three aspects, rather than contradictory or irrelevant."

Comrade deng xiaoping further stressed the moral, intellectual, physical all-round development talents is to cultivate socialist construction quality standards, he said: "our school is training talents for the socialist construction. Fosters the talent is there any quality standard? Yes. This is comrade MAO zedong said, should make the by the educators in moral education, intellectual education, sports development, several aspects have been become a worker with socialist consciousness of culture."

With socialist consciousness, is the older generation of proletarian revolutionaries of the ardent expectations of young people, also for our quality education as the expectations of the reform of facing the 21 st century.

Zhou Yuanqing to make the following summary: quality education has to improve the quality of talent as the important content and purpose of education is quality education. Starting from the concept of quality, constitute the basic elements of talent can be summarized as the knowledge, ability and quality. Talented person's quality can be divided into ideological and moral quality, cultural quality, professional quality and psychological quality, including ideological and moral quality is fundamental, is the soul and culture quality is the foundation. This is a new kind of talent has distinct era characteristic.

From the harmonious education thought in the history of the development at home and abroad, especially marxist ideas of harmonious education, harmonious education thoughts in the process of implementing quality education in our country realistic significance is obvious. Harmonious education in the micro level is in line with the essence of quality education. In quality-oriented education, there is no infiltration of harmonious education thought, is impossible to realize fundamental aim of improving students' quality in an all-round way.

\section{ACKNOWLEDGMENT}

Foundation item: the national social science fund for young (No.12CTQ043);

youth social science fund project in Guangdong province(No.GD11YTS02).

Author Introduction:

Liu Shuang was born in 1984, woman, in Guangzhou, instructors, master. The research direction: information management and information system; higher education.

Liu Chuanju was born in 1955, in Shandong, professor. The research direction: higher education.

\section{REFERENCES}

[1] Gu Mingyuan:Learning and reading the national medium - and longterm plan for education reform and development (20102020)[J].Rearch education,2010,(7) pp. 2-7

[2] Yang Qingfang,Cultural reflection of university teaching system,[M].Nanjing,Nanjing university of posts and telecommunications press, 2006,12 .

[3] The United Nations educational, scientific and cultural organization. Learn to survive. Shanghai translation press, 1979, pp. 225.

[4] Yang Qingfang,Cultural reflection of university teaching system,[M].Nanjing,Nanjing university of posts and telecommunications press,2006, pp. 16 24.

[5] Hou Dingkai,Higher education sociology ,[M],Nanning:Guangxi normal university press 2004, pp. 19-20.

[6] Xiong Zhixiang.On the innovation of higher education system[M].Guangdong: higher education press , 2002. pp. 66 71.

[7] Zhuo Qingjun,Fang Xiaodong.The development of education and human[M].Beijing:Education science press ,1995. pp. 68 69

[8] Wang Qingsong.The combination of humanities education. Science International Symposium and compound teachers ability[M].Hefei:Hefei industrial university press, 2007. pp. 141.

[9] He Zubin.The higher education ecological theory [M].Guangxi:Guangxi normal university press ,2005. pp. 209 210

[10] The editorial department of education study.2011 Annual report on Chinese education research frontiers and hot issues[J].Rearch education,2012,(1) pp. 2 8 